\title{
Resistência de genótipos de feijão-vagem ao ataque de Zabrotes subfasciatus (Bohemann, 1833) (Coleoptera: Chrysomelidae) ${ }^{1}$
}

\author{
Daline Benites Bottega ${ }^{2}$, Nara Elisa Lobato Rodrigues ${ }^{2}$, \\ Anderson Gonçalves da Silva ${ }^{2}$, Eduardo Neves Costa $^{2}$, Arlindo Leal Boiça Júnior ${ }^{2}$
}

\begin{abstract}
Resistance of string beans genotypes to the attack of Zabrotes subfasciatus (Bohemann, 1833) (Coleoptera: Chrysomelidae)

The string bean (Phaseolus vulgaris L.) can be attacked by worms of species such as the Zabrotes subfasciatus (Bohemann, 1833) (Coleoptera: Chrysomelidae), which directly affects the pods and seeds quality, making them unsuitable for consumption and commercialization. In order to find out an alternative way of controlling this insect, string bean genotypes and resistance levels to the Z. subfasciatus attack were evaluated, by using free and no-choice tests. The genotypes used were the UEGD7, UEG05, UEG06, UEG11, UEG13, UEG15, UEG18, UEG19 and UEG26, with four replications. In the free-choice test, the number of total, viable and unviable eggs and the attractiveness of adults by genotypes were evaluated. In the no-choice test, the number of total, viable and unviable eggs, dry weight consumption and dry weight consumption per insect, adult insect weight and longevity, period from egg to adult, sex ratio and number and percentage of insect emergence were evaluated. It was observed that the UEG05 genotype was the less preferred for oviposition by Z. subfasciatus, in the free-choice test. The UEG13 genotype showed to be highly resistant and the UEG05, UEG15 and UEG19 were moderately resistant. The UEG18 genotype was considered susceptible and the other ones highly susceptible to Z. subfasciatus.
\end{abstract}

KEY-WORDS: Phaseolus vulgaris L.; plant resistance to insects; bean worm.

\section{INTRODUÇÃO}

O feijão-vagem é uma hortaliça que pertence à mesma espécie botânica do feijão comum (Phaseolus vulgaris L.), o qual produz grãos secos (Filgueira 2000). Porém, se difere por ser uma hortaliça que fornece vagens imaturas para comercialização (Peixoto et al. 1993). É muito cultivada em estufa, o que possibilita colheitas em períodos de entressafra,

\section{RESUMO}

O feijão-vagem (Phaseolus vulgaris L.) pode sofrer ataque de carunchos, como os da espécie Zabrotes subfasciatus (Bohemann, 1833) (Coleoptera: Chrysomelidae), afetando, diretamente, a qualidade das vagens e sementes e deixandoas inviáveis para o consumo e comercialização. A fim de buscar uma alternativa para o controle deste inseto, foram determinados os tipos e graus de resistência, envolvidos em genótipos de feijão-vagem, ao ataque de Z. subfasciatus, em testes com e sem chance de escolha. Os genótipos utilizados foram UEGD7, UEG05, UEG06, UEG11, UEG13, UEG15, UEG18, UEG19 e UEG26, com quatro repetições. No teste com chance de escolha, os parâmetros avaliados foram o número de ovos viáveis, inviáveis e total e a atratividade dos adultos pelos genótipos. No teste sem chance de escolha, foram avaliados o número de ovos viáveis, inviáveis e total, massa seca consumida e massa seca consumida por inseto, massa e longevidade dos adultos, período de ovo a adulto, razão sexual e número e percentagem de insetos emergidos. Concluiu-se que o genótipo UEG05 foi o menos preferido por Z. subfasciatus, para oviposição, em teste com chance de escolha. O UEG13 foi altamente resistente e UEG05, UEG15 e UEG19 foram moderadamente resistentes. O UEG18 foi susceptível e os demais genótipos foram altamente susceptíveis a Z. subfasciatus.

PALAVRAS-CHAVE: Phaseolus vulgaris L.; resistência de plantas a insetos; caruncho.

conferindo, assim, maior rentabilidade ao produtor (Dequech et al. 2008).

Dentre os problemas que afetam a cultura, encontram-se as pragas, que podem atacá-la em todos os estádios, desde a semeadura, passando pelas fases vegetativa e reprodutiva, até a pós-colheita (Yokoyama 2006). A fauna de insetos associados ao feijão-vagem, citada por Castellane et al. (1988), não difere daquela relacionada ao feijoeiro comum, segundo Quintela (2002).

1. Trabalho recebido em jul./2012 e aceito para publicação em fev./2013 (nº registro: PAT 19343).

2. Universidade Estadual Paulista (Unesp), Faculdade de Ciências Agrárias e Veterinárias, Departamento de Fitossanidade, Jaboticabal, SP, Brasil.E-mails: daline4@bol.com.br, naraelr@hotmail.com, agroanderson.silva@yahoo.com.br, costa_ne@yahoo.com.br, aboicajr@fcav.unesp.br. 
Com potencial mais prejudicial à cultura, destacam-se a cigarrinha-verde Empoasca kraemeri (Ross \& Moore, 1957) (Hemiptera: Cicadellidae), a vaquinha Diabrotica speciosa (Germar) (Coleoptera: Chrysomelidae) e a mosca branca Bemisia tabaci (Gennadius, 1889) (Hemiptera: Aleyrodidae) (Yokoyama 1996). Já em condições de armazenamento, os prejuízos são causados pelos carunchos da família Chrysomelidae, destacando-se a espécie Zabrotes subfasciatus (Bohemann, 1833) (Coleoptera: Chrysomelidae) (Quintela 2002).

No Brasil, o ataque de Z. subfasciatus é generalizado, em todas as regiões produtoras (Vieira \& Yokoyama 2000), podendo, também, ocorrer ataques em campo (Bottega et al. 2012). Os danos causados são decorrentes da penetração e alimentação das larvas, no interior dos grãos, provocando perda de massa e redução do valor nutritivo e do grau de higiene do produto, depreciando a qualidade comercial, pela presença de insetos, ovos e excrementos, além de reduzir o poder germinativo das sementes (Quintela 2002).

O controle dessa praga pode ser realizado com inseticidas (Nascimento 2005). Entretanto, o uso de plantas resistentes apresenta várias vantagens, como o baixo custo, facilidade de utilização, ausência de contaminação dos grãos e compatibilidade com outras técnicas de controle (Lara 1991).

Vários estudos de resistência de plantas vêm sendo realizados como alternativa ao controle de carunchos (Barbosa et al. 2000, Mazzonetto \& Vendramim 2002, Campan \& Benrey 2006, Keito et al. 2007, Bottega et al. 2012), e o presente trabalho objetivou avaliar os graus de resistência de genótipos de feijão-vagem ao ataque de Z. subfasciatus, determinando os tipos de resistência.

\section{MATERIAL E MÉTODOS}

O experimento foi conduzido na Faculdade de Ciências Agrárias e Veterinárias da Universidade Estadual Paulista (Unesp), em Jaboticabal (SP), no Laboratório de Resistência de Plantas a Insetos do Departamento de Fitossanidade, de agosto a dezembro de 2011.

Os insetos utilizados foram oriundos de criação no laboratório, em feijão ( $P$. vulgaris) cultivar Bolinha, considerada susceptível (Boiça Júnior et al. 2002), em frascos de vidro de 5,0 L, fechados com tampas metálicas vazadas e revestidas com tela de náilon. A cada 30 dias, o material era peneirado e os adultos separados, para iniciar a infestação de novos frascos. A criação foi mantida em sala climatizada, sob temperatura de $27 \pm 2{ }^{\circ} \mathrm{C}$, umidade relativa de $75 \pm 5 \%$ e fotofase de 12 horas.

Os genótipos (tratamentos) utilizados foram: UEGD7, UEG05, UEG06, UEG11, UEG13, UEG15, UEG18, UEG19 e UEG26, tendo-se efetuado quatro repetições. Cada repetição foi constituída por 10,0 g de sementes de feijão-vagem, acondicionadas em recipientes plásticos cilíndricos de $3,9 \mathrm{~cm}$ de altura e $3,8 \mathrm{~cm}$ de diâmetro. Os testes foram realizados à temperatura de $25 \pm 1^{\circ} \mathrm{C}$, umidade relativa de $70 \pm 10 \%$ e fotofase de 12 horas.

Para o teste com chance de escolha, foram utilizadas arenas constituídas por bandejas circulares de alumínio, de 5,0 cm de altura e 30,0 cm de diâmetro, contendo, em seu interior, placas de isopor circular de 2,0 cm de altura e 29,4 cm de diâmetro, com aberturas circulares na periferia, onde acondicionaram-se recipientes plásticos, com 10,0 g de sementes de feijão-vagem de cada genótipo.

Esses recipientes ocuparam posições equidistantes de 3,5 cm ao centro da arena, onde foram liberados sete casais de Z. subfasciatus por genótipo, totalizando 126 insetos.

Para que os insetos não escapassem, as arenas foram cobertas com outra bandeja circular de mesmo diâmetro e vedadas com fita adesiva. A atratividade dos insetos pelos genótipos foi observada após 24 horas e sete dias. Passados os sete dias do início do experimento, os adultos foram retirados dos recipientes, sendo distribuídos, aleatoriamente, nas bandejas, com suas posições alternadas nas diferentes repetições, e realizou-se a contagem de ovos colocados pelos insetos.

No teste, foram avaliados o número de ovos viáveis, inviáveis e total e a atratividade dos adultos, após 24 horas e sete dias. Para o teste com chance de escolha, adotou-se o delineamento experimental de blocos ao acaso, com nove tratamentos e quatro repetições.

No teste sem chance de escolha, foram liberados sete casais de Z. subfasciatus recém-emergidos, por parcela, que permaneceram nos recipientes durante sete dias (Schoonhoven \& Cardona 1982). Após este período, realizou-se a contagem de ovos.

Aproximadamente 25 dias após o confinamento, iniciou-se a observação diária das amostras de feijão-vagem, a fim de efetuar a contagem e a retirada 
dos adultos emergidos, para determinar o período de desenvolvimento de ovo a adulto, nos genótipos estudados. Para a determinação da massa dos adultos, foi realizada pesagem individual, após a emergência, em balança analítica, dos 20 insetos que primeiro emergiram, e estes foram acondicionados em recipiente cilíndrico de vidro $(6,0 \mathrm{~cm}$ de altura e $3,0 \mathrm{~cm}$ de diâmetro), para a verificação de suas longevidades.

Estabeleceu-se uma alíquota de $10,0 \mathrm{~g}$ de grãos de cada genótipo e repetição, as quais foram secas em estufa, a $60^{\circ} \mathrm{C}$, por 48 horas. Este valor foi utilizado no cálculo da massa seca consumida pelos insetos, ao término da emergência dos adultos, por secagem das sementes em estufa, a $60^{\circ} \mathrm{C}$, por 48 horas. Pela diferença, em relação à massa das alíquotas não atacadas, determinou-se a massa seca consumida pelos insetos.

Os parâmetros avaliados nesse teste foram o número de ovos viáveis, inviáveis e total; massa seca consumida por todos os insetos e massa seca consumida por inseto; massa de machos e fêmeas; período de ovo a adulto de fêmeas, machos e total (fêmea + macho), ou seja, a somatória dos tempos que os insetos utilizaram para completar seus respectivos ciclos, se alimentando nos diferentes genótipos, sem considerar o sexo dos mesmos; longevidade de machos e fêmeas; razão sexual; número de insetos emergidos, fêmeas, machos e total (fêmea + macho) e percentagem de insetos emergidos.

Para o teste sem chance de escolha, foi utilizado o delineamento experimental inteiramente casualizado, com nove tratamentos e quatro repetições.
Os dados obtidos foram submetidos aos testes de normalidade (Kolmogorov-Smirnov) e homocedasticidade (Bartlett) (Silva \& Azevedo 2006). Foi realizada a análise de variância (Anova), pelo teste $\mathrm{F}$, sendo as médias comparadas pelo teste Tukey, a $5 \%$. Em caso de dados fora da normalidade e homocedásticos, estes foram transformados em $(x+0,5)^{1 / 2}$. Em caso de dados heterocedásticos, estes foram transformados em $\log (\mathrm{x}+5)$, em razão dos valores zeros obtidos. Realizou-se, também, no caso do teste sem chance, a análise de agrupamento hierárquico, utilizando-se o método "Single Linkage" e a distância euclidiana, como medida de dissimilaridade, além da análise dos componentes principais, a fim de se classificar os genótipos que apresentassem a máxima similaridade entre os grupos, com o uso do programa Statistica 7.0 (Statsoft 2004).

\section{RESULTADOS E DISCUSSÃO}

\section{Teste com chance de escolha}

O número total de adultos de $Z$. subfasciatus atraídos aos genótipos de feijão-vagem, após 24 horas da instalação do experimento, variou de 8,5 (UEG15) a 16,5 (UEGD7), e o número de insetos atraídos após sete dias variou de 9,5 (UEG05) a 13,0 (UEG19), porém, não houve diferenças significativas (Tabela 1). Em relação ao número total de ovos, observou-se diferença significativa, sendo o genótipo UEG05 menos ovipositado $(64,5)$, diferenciando-se do UEG19 $(132,5)$ (Tabela 1).

Tabela 1. Número médio ( \pm EP) de adultos de Zabrotes subfasciatus, atraídos após 24 horas e sete dias da instalação do experimento, e número de ovos viáveis, inviáveis e total, em sementes de genótipos de feijão-vagem, em testes com e sem chance de escolha, à temperatura de $25 \pm 1^{\circ} \mathrm{C}$, umidade relativa de $70 \pm 10 \%$ e fotofase de 12 horas (Jaboticabal, SP, 2011).

\begin{tabular}{|c|c|c|c|c|c|c|c|c|}
\hline \multirow{3}{*}{ Genótipos } & \multicolumn{5}{|c|}{ Com chance } & \multicolumn{3}{|c|}{ Sem chance } \\
\hline & \multicolumn{2}{|c|}{$\mathrm{N}^{\circ}$ de insetos atraídos } & \multicolumn{3}{|c|}{$\mathrm{N}^{\mathrm{o}}$ de ovos } & \multicolumn{3}{|c|}{$\mathrm{N}^{\mathrm{o}}$ de ovos } \\
\hline & 24 horas & 7 dias & Total & Viável & Inviável & Total & Viável & Inviável \\
\hline UEGD7 & $16,5 \pm 2,53$ & $12,5 \pm 2,90$ & $94,2 \pm 13,51 \mathrm{ab}$ & $59,5 \pm 10,49$ & $34,7 \pm 4,03 \mathrm{abc}$ & $109,5 \pm 10,88$ & $71,7 \pm 7,86$ & $37,7 \pm 4,33$ \\
\hline UEG05 & $11,0 \pm 2,97$ & $9,5 \pm 0,82$ & $64,5 \pm 14,35 \mathrm{a}$ & $37,5 \pm 9,82$ & $27,0 \pm 5,64 \mathrm{a}$ & $81,2 \pm 11,29$ & $57,2 \pm 2,78$ & $24,0 \pm 9,09$ \\
\hline UEG06 & $14,2 \pm 2,06$ & $11,0 \pm 1,35$ & $96,7 \pm 15,05 a b$ & $65,2 \pm 8,23$ & $31,5 \pm 9,46 a b$ & $63,5 \pm 17,74$ & $34,2 \pm 11,65$ & $29,2 \pm 6,51$ \\
\hline UEG11 & $11,2 \pm 2,06$ & $10,7 \pm 2,08$ & $107,2 \pm 19,70 a b$ & $67,5 \pm 13,61$ & $60,7 \pm 7,17 \mathrm{abc}$ & $68,5 \pm 4,25$ & $53,7 \pm 2,66$ & $14,7 \pm 1,80$ \\
\hline UEG13 & $9,0 \pm 1,75$ & $10,7 \pm 1,55$ & $89,2 \pm 16,90 \mathrm{ab}$ & $32,7 \pm 13,68$ & $56,5 \pm 3,40 \mathrm{bcd}$ & $58,0 \pm 8,91$ & $36,0 \pm 3,84$ & $22,0 \pm 5,44$ \\
\hline UEG15 & $8,5 \pm 4,33$ & $11,5 \pm 0,41$ & $112,5 \pm 30,46 a b$ & $51,7 \pm 23,41$ & $60,7 \pm 7,09 \mathrm{~cd}$ & $56,0 \pm 5,24$ & $43,2 \pm 3,92$ & $12,7 \pm 2,25$ \\
\hline UEG18 & $9,0 \pm 2,68$ & $7,0 \pm 0,29$ & $82,0 \pm 14,20 a b$ & $37,0 \pm 10,31$ & $45,0 \pm 4,53 \mathrm{abcd}$ & $62,0 \pm 16,46$ & $31,2 \pm 10,66$ & $30,7 \pm 6,10$ \\
\hline UEG19 & $14,5 \pm 3,12$ & $13,0 \pm 2,90$ & $132,5 \pm 11,86 b$ & $60,2 \pm 6,41$ & $72,2 \pm 7,25 \mathrm{~d}$ & $44,5 \pm 12,05$ & $30,7 \pm 12,99$ & $13,7 \pm 2,46$ \\
\hline UEG26 & $9,2 \pm 1,23$ & $8,0 \pm 1,60$ & $107,2 \pm 11,38 \mathrm{ab}$ & $53,7 \pm 2,43$ & $53,5 \pm 8,97 \mathrm{abcd}$ & $73,7 \pm 20,49$ & $46,5 \pm 14,89$ & $27,2 \pm 5,70$ \\
\hline Teste $\mathrm{F}$ & $1,04^{\mathrm{ns}}$ & $1,04^{\mathrm{ns}}$ & $2,24^{*}$ & $1,85^{\text {ns }}$ & $6,73 * *$ & $2,06^{\mathrm{ns}}$ & $2,32^{\mathrm{ns}}$ & $2,59^{\mathrm{ns}}$ \\
\hline C.V. $(\%)$ & 46,16 & 38,02 & 26,48 & 36,92 & 24,76 & 37,93 & 40,50 & 45,34 \\
\hline
\end{tabular}

Médias seguidas da mesma letra, na coluna, não diferem entre si, pelo teste Tukey, a $5 \%$. ${ }^{*} *$ e ns: significativo a $5 \%$ e $1 \%$ e não significativo, respectivamente. 
Bottega et al. (2012), avaliando genótipos de feijão-vagem, observaram maior número de ovos $(131,8$ a 208,0$)$ que o encontrado nesta pesquisa. Miranda et al. (2002), Ribeiro-Costa et al. (2007) e Baldin \& Pereira (2010) identificaram menor oviposição em feijoeiro comum. Boiça Júnior et al. (2002) encontraram valores mais elevados de oviposição $(154,8$ a 215,9), em genótipos de feijoeiro comum, que os encontrados em feijão-vagem, nesta pesquisa.

A variação da oviposição em Phaseolus spp. pode ocorrer porque as fêmeas de $Z$. subfasciatus são capazes de utilizar estímulos visuais (cor, forma, tamanho) e químicos (nutrientes, substâncias atrativas e/ou repelentes), na busca e escolha do hospedeiro, conforme já demonstrado para outras espécies, por Messina (1990). Segundo Lara (1991), a forma como Z. subfasciatus fixa a postura dos seus ovos nos grãos, não deixando-os soltos, pode ser um indicativo de que estes insetos, provavelmente, selecionam o hospedeiro, pois os insetos apresentam, como regra geral, o comportamento de ovipositar em substratos que garantam o desenvolvimento das larvas, assegurando, desta forma, a sobrevivência da espécie, segundo o princípio de Hopkins.

\section{Teste sem chance de escolha}

Não houve diferenças significativas nos valores referentes ao número de ovos viáveis, inviáveis e total, demonstrando, assim, que os genó- tipos avaliados foram igualmente ovipositados por Z. subfasciatus (Tabela 1).

Os dados da razão sexual, massa seca consumida por inseto, número de adultos emergidos e percentagem de adultos emergidos não apresentaram diferenças estatísticas significativas entre os genótipos (Tabela 2).

A massa seca consumida por todos os insetos apresentou diferença significativa, sendo o UEG13 menos consumido $(0,67 \mathrm{~g})$ e o UEG05 mais consumido (1,56 g) (Tabela 2). Baldin \& Pereira (2010) relatam que menores médias de consumo indicam a ocorrência de não preferência para alimentação. Lara (1991) relatou a dificuldade de distinção entre a não preferência para alimentação e a antibiose, pois as larvas possuem a necessidade de se alimentar normalmente, o que pode acarretar efeitos adversos à sua biologia. Porém, como houve baixo consumo, trata-se de não preferência para alimentação, podendo ou não estar ocorrendo, conjuntamente, a antibiose.

A massa e a longevidade de machos não apresentaram diferenças estatísticas significativas (Tabela 3). Já com relação à massa de fêmeas, o genótipo UEG13 apresentou a menor média $(3,1 \mathrm{mg})$ e as maiores foram dos genótipos UEGD7 $(3,7 \mathrm{mg})$, UEG26 (3,6 mg), UEG19 (3,6 mg) e UEG05 (3,6 mg) (Tabela 3). As menores massas podem ter ocorrido em função de um efeito antibiótico do genótipo sobre a praga. Baldin \& Pereira (2010) relatam que a redução na massa de adultos de $Z$. subfasciatus é um indicativo de resistência, em genótipos de feijoeiro.

Tabela 2. Número médio ( \pm EP) da razão sexual, massa seca consumida, massa seca consumida por inseto, número de adultos emergidos e percentagem de adultos emergidos de Zabrotes subfasciatus, em genótipos de feijão-vagem, à temperatura de $25 \pm 1^{\circ} \mathrm{C}$, umidade relativa de $70 \pm 10 \%$ e fotofase de 12 horas (Jaboticabal, SP, 2011).

\begin{tabular}{cccccc}
\hline \multirow{2}{*}{ Genótipos } & Razão sexual & \multicolumn{2}{c}{$\begin{array}{c}\text { Massa seca } \\
\text { consumida }\end{array}$} & $\begin{array}{c}\text { Massa seca consu- } \\
\text { mida por inseto }^{(1)}\end{array}$ & $\begin{array}{c}\text { Adultos emergidos } \\
\text { Adultos emergidos }\end{array}$ \\
\cline { 3 - 6 } & & $\mathrm{g}$ & $\mathrm{mg}$ & $\mathrm{n}^{\text {o }}$ & $\%$ \\
\hline UEGD7 & $0,52 \pm 0,02$ & $1,47 \pm 0,26 \mathrm{ab}$ & $34,56 \pm 0,01$ & $48,5 \pm 8,03$ & $66,4 \pm 4,99$ \\
UEG05 & $0,48 \pm 0,01$ & $1,56 \pm 0,19 \mathrm{~b}$ & $35,26 \pm 0,01$ & $50,2 \pm 8,77$ & $77,9 \pm 13,67$ \\
UEG06 & $0,45 \pm 0,01$ & $0,95 \pm 0,16 \mathrm{ab}$ & $54,78 \pm 0,01$ & $18,5 \pm 2,90$ & $53,1 \pm 4,34$ \\
UEG11 & $0,58 \pm 0,03$ & $1,34 \pm 0,17 \mathrm{ab}$ & $29,76 \pm 0,01$ & $45,8 \pm 6,63$ & $83,9 \pm 6,41$ \\
UEG13 & $0,45 \pm 0,06$ & $0,67 \pm 0,17 \mathrm{a}$ & $96,95 \pm 0,07$ & $28,0 \pm 12,72$ & $67,7 \pm 6,41$ \\
UEG15 & $0,45 \pm 0,03$ & $1,32 \pm 0,09 \mathrm{ab}$ & $51,94 \pm 0,01$ & $29,8 \pm 6,38$ & $72,1 \pm 7,35$ \\
UEG18 & $0,48 \pm 0,05$ & $1,39 \pm 0,27 \mathrm{ab}$ & $64,03 \pm 0,01$ & $22,5 \pm 2,36$ & $72,0 \pm 3,82$ \\
UEG19 & $0,47 \pm 0,06$ & $1,34 \pm 0,07 \mathrm{ab}$ & $64,14 \pm 0,02$ & $24,0 \pm 4,42$ & $76,2 \pm 10,10$ \\
UEG26 & $0,46 \pm 0,08$ & $1,14 \pm 0,19 \mathrm{ab}$ & $51,72 \pm 0,02$ & $30,5 \pm 8,01$ & $65,7 \pm 12,03$ \\
\hline Teste F & $1,04^{\text {ns }}$ & $2,29^{*}$ & $1,00^{\text {ns }}$ & $2,65^{\text {ns }}$ & $1,18^{\text {ns }}$ \\
\hline C.V. $(\%)$ & 18,97 & 29,59 & 0,71 & 44,39 & 23,08 \\
\hline
\end{tabular}

Médias seguidas da mesma letra, na coluna, não diferem entre si, pelo teste Tukey, a 5\%. ${ }^{(1)}$ Para análise, os dados foram transformados em log (x+5). ${ }^{\text {e ns. } \text { significativo }}$ a $5 \%$ e não significativo, respectivamente. 
Tabela 3. Número médio ( \pm EP) da massa, período de ovo a adulto e longevidade de machos e fêmeas de Zabrotes subfasciatus criados em genótipos de feijão-vagem, à temperatura de $25 \pm 1{ }^{\circ} \mathrm{C}$, umidade relativa de $70 \pm 10 \%$ e fotofase de 12 horas (Jaboticabal, SP, 2011).

\begin{tabular}{|c|c|c|c|c|c|c|c|}
\hline \multirow{2}{*}{ Genótipos } & $\begin{array}{l}\text { Massa de } \\
\text { machos }\end{array}$ & $\begin{array}{l}\text { Massa de } \\
\text { fêmeas }\end{array}$ & $\begin{array}{l}\text { Período ovo a } \\
\text { adulto machos }\end{array}$ & $\begin{array}{l}\text { Período ovo a } \\
\text { adulto fêmeas }\end{array}$ & $\begin{array}{l}\text { Período ovo a } \\
\text { adulto total }^{(1)}\end{array}$ & $\begin{array}{l}\text { Longevidade } \\
\text { de } \text { machos }^{(1)}\end{array}$ & $\begin{array}{l}\text { Longevidade } \\
\text { de fêmeas }\end{array}$ \\
\hline & \multicolumn{2}{|c|}{$\mathrm{mg}$} & \multicolumn{5}{|c|}{ dias } \\
\hline UEGD7 & $2,1 \pm 0,07$ & $3,7 \pm 0,08 \mathrm{c}$ & $38,3 \pm 0,25 \mathrm{a}$ & $38,4 \pm 0,08 \mathrm{a}$ & $38,3 \pm 0,14 \mathrm{a}$ & $13,4 \pm 0,82$ & 20,3 \\
\hline UEG05 & $2,0 \pm 0,07$ & $3,6 \pm 0,09 \mathrm{bc}$ & $42,3 \pm 0,35 \mathrm{~cd}$ & $42,2 \pm 0,41 \mathrm{~cd}$ & $42,2 \pm 0,38 \mathrm{bc}$ & $12,7 \pm 0,87$ &, $67 \mathrm{a}$ \\
\hline UEG06 & $2,1 \pm 0,08$ & $3,4 \pm 0,09 a b c$ & $39,2 \pm 0,2 \mathrm{a}$ & $40,0 \pm 0,32 \mathrm{abc}$ & $39,6 \pm 0,25 \mathrm{a}$ & $13,9 \pm 0,46$ & $20,8 \pm 1,41 \mathrm{c}$ \\
\hline UEG11 & $2,0 \pm 0,05$ & $3,4 \pm 0,09 a b c$ & $39,4 \pm 0,17 \mathrm{ab}$ & $39,7 \pm 0,26 \mathrm{ab}$ & $39,5 \pm 0,18 \mathrm{a}$ & $13,8 \pm 0,28$ & $19,6 \pm 1,15 \mathrm{bc}$ \\
\hline UEG13 & $2,0 \pm 0,06$ & $3,1 \pm 0,10 \mathrm{a}$ & $42,6 \pm 0,52 \mathrm{~cd}$ & $43,4 \pm 1,05 \mathrm{de}$ & $43,0 \pm 0,43 \mathrm{~cd}$ & $14,6 \pm 0,87$ & $13,6 \pm 1,87 \mathrm{ab}$ \\
\hline UEG15 & $2,0 \pm 0,06$ & $3,4 \pm 0,09 a b c$ & $43,4 \pm 0,31 \mathrm{~d}$ & $44,6 \pm 0,24 \mathrm{e}$ & $44,0 \pm 0,27 \mathrm{~d}$ & $13,9 \pm 0,90$ & $17,8 \pm 0,83 \mathrm{abc}$ \\
\hline UEG18 & $1,9 \pm 0,08$ & $3,2 \pm 0,07 \mathrm{ab}$ & $39,4 \pm 0,46 \mathrm{a}$ & $40,0 \pm 0,42 \mathrm{abc}$ & $39,6 \pm 0,14 \mathrm{a}$ & & $19,5 \pm 1,72 \mathrm{bc}$ \\
\hline UEG19 & $2,0 \pm 0,06$ & $3,6 \pm 0,09 \mathrm{bc}$ & $43,2 \pm 0,17 \mathrm{~cd}$ & $44,0 \pm 0,48 \mathrm{de}$ & $43,6 \pm 0,22 \mathrm{~cd}$ & $11,8 \pm 1,16$ & $19,6 \pm 0,74 \mathrm{bc}$ \\
\hline UEG26 & $2,0 \pm 0,08$ & $3,6 \pm 0,09 \mathrm{bc}$ & $41,3 \pm 0,77 \mathrm{bc}$ & $41,1 \pm 0,32 \mathrm{bc}$ & $41,2 \pm 0,52 \mathrm{~b}$ & $14,4 \pm 0,61$ & $19,0 \pm 1,51 \mathrm{bc}$ \\
\hline Teste F & $1,22^{\mathrm{ns}}$ & $4,08 * *$ & $23,35 * *$ & $21,32 * *$ & $45,32 * *$ & $1,48^{\mathrm{ns}}$ & $4,99 * *$ \\
\hline C.V. $(\%)$ & 14,70 & 11,66 & 0,97 & 2,28 & 0,73 & 14,70 & 19,27 \\
\hline
\end{tabular}

Médias seguidas da mesma letra, na coluna, não diferem entre si, pelo teste Tukey, a $5 \%$. ${ }^{1}$ Para análise, os dados foram transformados em $(\mathrm{x}+0,5)^{1 / 2}$. $* * \mathrm{e}^{\mathrm{ns}}$ : significativo a $1 \%$ e não significativo, respectivamente.

O período de desenvolvimento de ovo a adulto de machos, fêmeas e total apresentou diferenças significativas, sendo que os genótipos UEGD7, UEG06, UEG18 e UEG11 encurtaram o ciclo da praga, com médias de período total (ovo a adulto) variando de 38,3 a 39,6 dias, diferindo dos genótipos UEG05, UEG13, UEG15 e UEG19, que alongaram o ciclo, com período total variando de 42,2 a 44,0 dias. $\mathrm{O}$ genótipo UEG 26 se comportou de forma intermediária, com período total de ovo a adulto de 41,2 dias (Tabela 3).

Lara (1997), Wanderley et al. (1997), Mazzonetto \& Vendramim (2002) e Moraes et al. (2011) observaram tempo prolongado de desenvolvimento de Z. subfasciatus, em genótipos de feijão comum, demonstrando resistência destes materiais, por afetarem o desenvolvimento do inseto. Baldin \& Pereira (2010) também verificaram prolongamento do período de ovo a adulto de Z. subfasciatus, quando criados nos genótipos Arc.1, Arc.2, Arc.3, Arc.4 e Arc.1S, indicando a ocorrência de não preferência para alimentação e/ ou antibiose.

Os genótipos UEG05 e UEG13, além de maiores durações dos períodos de ovo a adulto, também apresentaram menor longevidade de fêmeas (12,9 e 13,6 dias, respectivamente), se comparados aos demais genótipos, diminuindo as possibilidades de oviposição do inseto. Nos demais genótipos, a longevidade de fêmeas variou de 17,8 a 20,8 dias
(Tabela 3). Segundo Boiça Júnior et al. (2002), genótipos que atingem maior longevidade possuem substâncias que proporcionam maiores acúmulos de reserva para que isto ocorra.

Mazzonetto \& Vendramim (2002) relatam que genótipos que apresentam maior período de desenvolvimento (ovo a adulto) e menor massa e longevidade sugerem a ocorrência de não preferência para alimentação e/ou antibiose. O genótipo UEG13 apresentou estes três fatores e o UEG05 menor longevidade e período de desenvolvimento, sugerindo serem resistentes, se comparados aos demais genótipos avaliados.

Por meio da análise de agrupamento hierárquico, observou-se que houve distinção entre os genótipos, dividindo-os em grupos, de acordo com o grau de similaridade entre os mesmos (Figura 1). Deste modo, a partir do gráfico da distância de ligação dos grupos (Figura 2), fixou-se a distância euclidiana em 3,22, sugerindo a divisão dos genótipos avaliados em cinco grupos distintos: UEG13; UEG05, UEG15 e UEG19; UEG18; UEG06, UEG11 e UEG26; e UEGD7 (Figura 1).

Observando-se os resultados obtidos pela análise dos componentes principais, pôde-se verificar que o primeiro componente principal (CP1) concentrou $45,31 \%$ da variabilidade contida nas variáveis originais, sendo os seguintes parâmetros aqueles que mais contribuíram: longevidade de fêmeas (LF), massa de machos (PM), período de ovo 


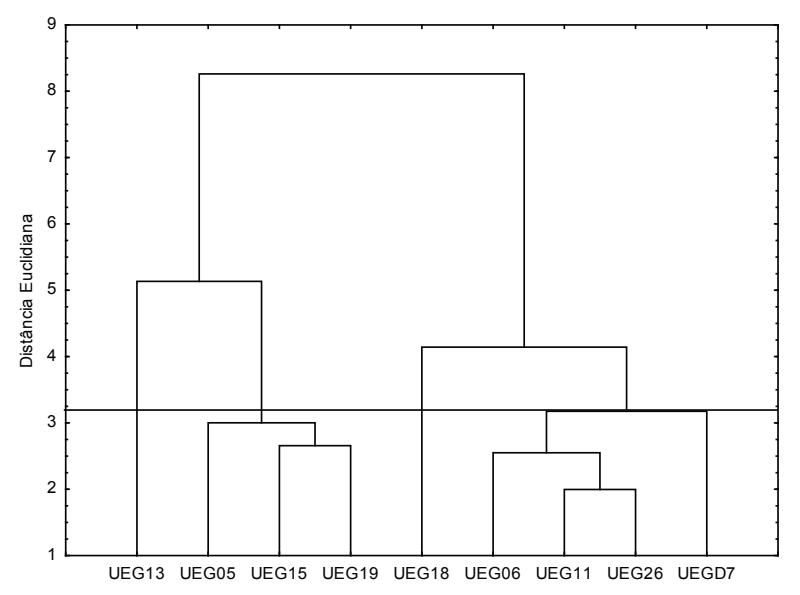

Figura 1. Dendrograma baseado nos parâmetros biológicos de Zabrotes subfasciatus alimentado com genótipos de feijão-vagem. Agrupamento efetuado segundo o método de Ward, tendo a distância euclidiana como medida de dissimilaridade.

a adulto de fêmeas (POAF), período de ovo a adulto de machos (POAM) e período total de ovo a adulto (POAT). O segundo componente principal (CP2) concentrou $25,86 \%$ da variabilidade presente nas variáveis originais, sendo os parâmetros biológicos que mais contribuíram a longevidade de machos (LM), massa de fêmeas (PF) e massa seca consumida (MSC) (Figura 3a).

Nota-se que, na análise dos componentes principais, foi possível obter um resultado comum à análise de agrupamento hierárquico, sendo que os genótipos do mesmo grupo apresentaram-se próximos e nos mesmos quadrantes (Figura 3b). Demonstrou-se que, dentro de cada grupo, os genótipos apresentam similaridade, com os mesmos componentes em comum (Figura 3a), os quais contribuíram para a divisão dos grupos.

O genótipo UEG13 isolou-se no terceiro quadrante, devido aos menores valores de massa seca consumida e massa de fêmeas e maiores períodos de desenvolvimento de ovo a adulto de fêmeas, machos e total (Figura 3).

Os genótipos UEG05, UEG15 e UEG19 se isolaram no segundo quadrante, destacando-se por apresentarem maiores períodos de desenvolvimento de ovo a adulto de fêmeas, machos e total (Figura 3).

Os fatores que levaram UEG18 ao primeiro quadrante foram a alta longevidade de fêmeas e o baixo período de desenvolvimento de ovo a adulto de fêmeas, machos e total (Figura 3).

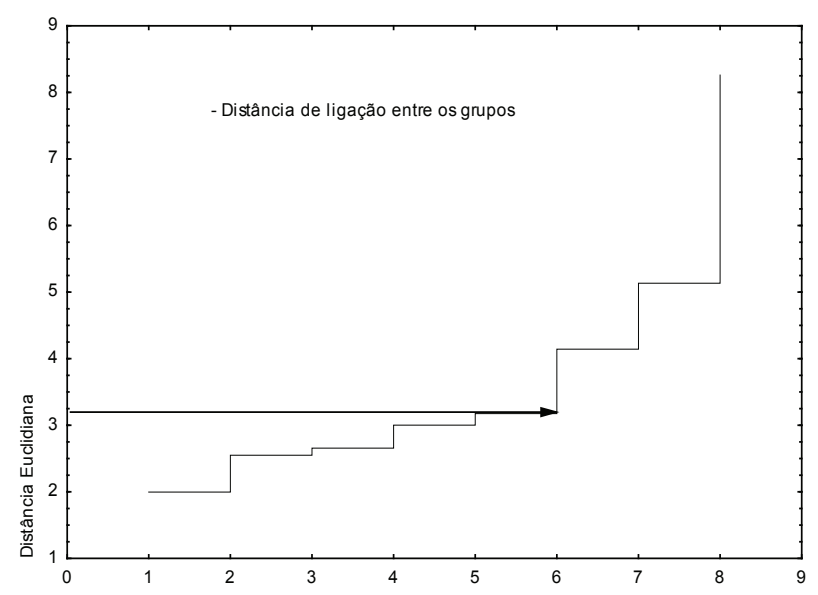

Figura 2. Distância de ligação dos grupos, utilizando-se o método de agrupamento de Ward, tendo a distância euclidiana como medida de dissimilaridade. A seta indica a distância euclidiana utilizada para a separação dos grupos.

No quarto quadrante, apresentaram-se os genótipos UEG06, UEG11 e UEG26, devido ao menor período de desenvolvimento de ovo a adulto de fêmeas, machos e total (Figura 3).

O genótipo UEGD7 ficou no primeiro quadrante, em razão dos maiores valores de massa seca consumida, massa de fêmeas e longevidade de fêmeas, e menor período de desenvolvimento de ovo a adulto de fêmeas, machos e total, sendo, assim, o material que mais beneficiou o desenvolvimento do inseto (Figura 3).

Observando-se as análises, constatou-se que o genótipo UEG13 alongou o período de desenvolvimento de ovo a adulto do inseto e obteve menor massa consumida e massa de fêmeas, além de apresentar baixa longevidade de fêmeas, como, também, observado na análise univariada, indicando, assim, que este genótipo possui resistência a $Z$. subfasciatus. Baldin \& Lara (2004) relataram que o baixo consumo, aliado à menor massa e elevado período de desenvolvimento dos insetos provenientes dos grãos, confirmam a ocorrência de antibiose.

Os genótipos UEG05, UEG15 e UEG19 destacaram-se por apresentar maiores períodos de desenvolvimento de ovo a adulto de fêmeas, machos e total, demonstrando, assim, que estes genótipos afetaram negativamente a biologia de Z. subfasciatus, resultado também observado na análise univariada, confirmando, assim, que estes genótipos possuem resistência. 

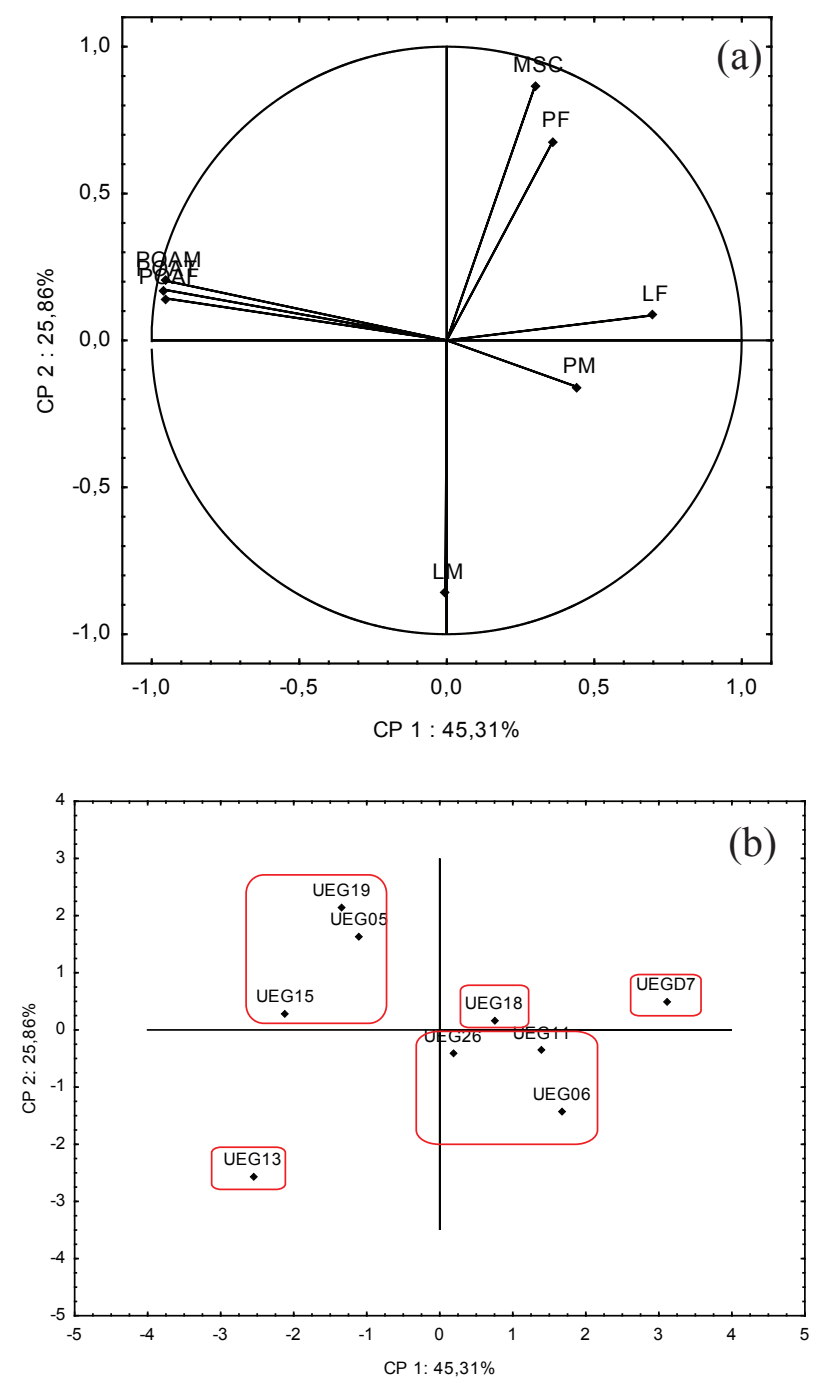

Figura 3. Distribuição dos parâmetros biológicos (a) e genótipos de feijão-vagem (b), de acordo com a análise dos componentes principais de parâmetros biológicos de Zabrotes subfasciatus criados com diferentes genótipos de feijão-vagem. PM: peso de machos; PF: peso de fêmeas; POAM: período de ovo a adulto de machos; POAF: período de ovo a adulto de fêmeas; POAT: período de ovo a adulto total; LM: longevidade de machos; LF: longevidade de fêmeas; MSC: massa seca consumida.

A partir dos resultados obtidos nas análises de agrupamento e dos componentes principais, foi possível classificar os genótipos de feijão-vagem da seguinte forma, de acordo com o grau de resistência do tipo, não preferência para alimentação e/ou antibiose: UEG13 (altamente resistente); UEG05, UEG15 e UEG19 (moderadamente resistentes); UEG18 (susceptível); UEG06, UEG 11, UEG26 e UEGD7 (altamente susceptíveis).

\section{CONCLUSÕES}

1. UEG05 foi o genótipo menos preferido por Z. subfasciatus para oviposição, em teste com chance de escolha.

2. UEG13 apresentou-se como genótipo resistente, do tipo não preferência para alimentação e/ou antibiose.

3. UEG05, UEG15 e UEG19 mostraram-se como genótipos moderadamente resistentes, do tipo não preferência para alimentação e/ou antibiose.

4. UEG18 foi classificado como genótipo susceptível e os demais como altamente susceptíveis.

\section{REFERÊNCIAS}

BALDIN, E. L. L.; LARA, F. M. Efeito de temperaturas de armazenamento e de genótipos de feijoeiro sobre a resistência a Acanthoscelides obtectus (Say) (Coleoptera: Bruchidae). Neotropical Entomology, Londrina, v. 33, n. 3 , p. 365-369, 2004.

BALDIN, E. L. L.; PEREIRA, J. M. Resistência de genótipos de feijoeiro a Zabrotes subfasciatus (Bohemann, 1833) (Coleoptera: Bruchidae). Ciência e Agrotecnologia, Lavras, v. 34, n. 6, p. 1507-1513, 2010.

BARBOSA, F. R. et al. Estabilidade da resistência a Zabrotes subfasciatus pela proteína arcelina, em feijoeiro. Pesquisa Agropecuária Brasileira, Brasília, DF, v. 35, n. 5, p. 895-900, 2000.

BOIÇA JÚNIOR, A. L.; BOTELHO, A. C. G.; TOSCANO, L. C. Comportamento de genótipos de feijoeiro ao ataque de Zabrotes subfasciatus (Boheman, 1833) (Coleoptera: Bruchidae) em condições de laboratório. Arquivos do Instituto Biológico, São Paulo, v. 69, n. 2, p. 51-55, 2002.

BOTTEGA, D. B. et al. Resistência de genótipos de feijão-vagem ao ataque de bruquíneos, em condições de laboratório. Revista Caatinga, Mossoró, v. 25, n. 1, p. 92-97, 2012.

CAMPAN, E. D. M.; BENREY, B. Effects of seed type and bruchid genotype on the performance and oviposition behavior of Zabrotes subfasciatus (Coleoptera: Bruchidae). Insect Science, Shanghai, v. 13, n. 4, p. 309-318, 2006.

CASTELlANE, P. D.; VIEIRA, R. D.; CARVALHO, N. M. Feijão-de-vagem (Phaseolus vulgaris L.): cultivo e produção de sementes. Jaboticabal: Unesp, 1988.

DEQUECH, S. T. B. et al. Fitotoxicidade causada por inseticidas botânicos em feijão-de-vagem (Phaseolus vulgaris L.) cultivado em estufa plástica. Revista da FZVA, Uruguaiana, v. 15, n. 1, p. 71-80, 2008. 
FILGUEIRA, F. A. R. Novo manual de olericultura: agrotecnologia moderna na produção e comercialização de hortaliças. Viçosa: UFV, 2000.

KEITO, N. et al. Assessment of the importance of alphaamylase inhibitor-2 in bruchid resistance of wild common bean. Theoretical and Applied Genetics, Stuttgart, v. 114, n. 4, p. 755-764, 2007.

LARA, F. M. Princípios de resistência de plantas a insetos. 2. ed. São Paulo: Ícone, 1991.

LARA, F. M. Resistance of wild and near isogenic bean lines with arcelin variants to Zabrotes subfasciatus (Boheman): I - winter crop. Anais da Sociedade Entomológica do Brasil, Londrina, v. 26, n. 3, p. 551560, 1997.

MAZZONETTO, F.; VENDRAMIN, J. D. Aspectos biológicos de Zabrotes subfasciatus (Boh.) (Coleoptera: Bruchidae) em genótipos de feijoeiro com e sem arcelina. Neotropical Entomology, Londrina, v. 31, n. 3, p. 435439, 2002.

MESSINA, F. J. Components of host choice by two Rhagoletis species (Diptera, Tephritidae) in Utah. Journal of the Kansas Entomological Society, Lawrence, v. 63, n. 1, p. 80-87, 1990.

MIRANDA, J. E.; TOSCANO, L. C.; FERNANDES, M. G. Avaliação da resistência de diferentes genótipos de Phaseolus vulgaris a Zabrotes subfasciatus (Boh.) (Coleoptera: Bruchidae). Boletín de Sanidad Vegetal Plagas, Madrid, v. 28, n. 1, p. 571-576, 2002.

MORAES, C. P. B. et al. Determinação dos tipos de resistência nos genótipos de feijoeiro ao ataque de Zabrotes subfasciatus (Coleoptera: Bruchidae). Ceres, Viçosa, v. 58, n. 4, p. 419-424, 2011.

NASCIMENTO, W. M. Produção de sementes de hortaliças para a agricultura familiar. Brasília, DF: Embrapa Hortaliças, 2005. (Circular técnica, 35).

PEIXOTO, N. et al. Avaliação de cultivares arbustivas de feijão-vagem em Anápolis. Horticultura Brasileira, Brasília, DF, v. 11, n. 2, p. 151-152, 1993.
QUINTELA, E. D. Manual de identificação dos insetos e outros invertebrados pragas do feijoeiro. Santo Antônio de Goiás: Embrapa Arroz e Feijão, 2002. (Documentos, 142).

RIBEIRO-COSTA, C. S.; PEREIRA, P. R. da S.; ZUKOVSKI, L. Desenvolvimento de Zabrotes subfasciatus (Boh.) (Coleoptera: Chrysomelidae, Bruchinae) em genótipos de Phaseolus vulgaris L. (Fabaceae) cultivados no Estado do Paraná e contendo arcelina. Neotropical Entomology, Londrina, v. 36, n. 4, p. 560-564, 2007.

SCHOONHOVEN, A.; CARDONA, C. Low levels of resistance to the Mexican bean weevil in dry bean. Journal of Economic Entomology, Lanham, v. 76, n. 4, p. 567-569, 1982.

SILVA, F. A. S.; AZEVEDO, C. A. V. A. New version of the Assistat - Statistical Assistance Software. In: WORLD CONGRESS ON COMPUTERS IN AGRICULTURE, 4., 2006, Orlando. Proceedings... Orlando: American Society of Agricultural and Biological Engineers, 2006. p. 393-396.

STATSOFT. Data analysis software system and user's manual. Version 7.0. Tulsa: StatSoft Inc., 2004.

VIEIRA, E. H. N.; YOKOYAMA, M. Colheita, processamento e armazenamento. In: VIEIRA, E. H. N.; RAVA, C. A. Sementes de feijão: produção e tecnologia. Santo Antônio de Goiás: Embrapa Arroz e Feijão, 2000. p. 233-248.

WANDERLEY, V. S.; OLIVEIRA, J. V.; ANDRADE JÚNIOR, M. L. Resistência de cultivar e linhagens de Phaseolus vulgaris L. a Zabrotes subfasciatus (Boh.) (Coleoptera: Bruchidae). Anais da Sociedade Entomológica do Brasil, Londrina, v. 26, n. 2, p. 315320, 1997.

YOKOYAMA, M. Pragas. In: VIEIRA, C.; PAULA JÚNIOR, T. J.; BORÉM, A. Feijão. 2. ed. Viçosa, MG: UFV, 2006. p. 341-357.

YOKOYAMA, M. Principais pragas e seu controle. In: ARAÚJO, R. S. et al. Cultura do feijoeiro comum no Brasil. Piracicaba: Potafos, 1996. p. 771-786. 